\title{
Isolation, purification and flow cytometric analysis of human intrahepatic lymphocytes using an improved technique
}

\author{
Mohamed A Morsy ${ }^{1}$, Paul J Norman ${ }^{2, *}$, Ragai Mitry ${ }^{1}$, Mohamed Rela ${ }^{1}$, Nigel D Heaton ${ }^{1}$ and \\ Robert W Vaughan ${ }^{2}$ \\ ${ }^{1}$ Institute of Liver Study, King's College Hospital, London, UK and ${ }^{2}$ Clinical Transplantation Laboratories, \\ Guy's Hospital, London, UK
}

\begin{abstract}
Intrahepatic lymphocytes (IHL) with their diverse and distinctive subsets emphasise the importance of the liver as a site of immunological activity, but special care is required for their isolation and characterisation. Protocols for IHL isolation, purification and FACS analysis were devised and compared with published extraction protocols. We have reduced the time that $\mathrm{IHL}$ are exposed to potentially damaging enzymes during extraction and purified specific subsets using monoclonal antibody (mAb)-coated magnetic microbeads. This has yielded IHL populations with higher viability than previously described protocols $(92-95 \%$, compared with 39-86\%). Flow cytometric characterisation of IHL subset immunophenotypes was optimised by combining CD45 staining (fluorescence gating) with traditional light scatter properties. Using a panel of mAb and liver biopsies obtained from 23 cadaveric liver transplant donors, we show that the normal liver contains a heterogeneous IHL population with distinctive phenotypes. CD8 ${ }^{+}$IHL was the predominant population with a mean CD4/CD8 ratio of 1:1.7. Up to $40 \%$ of IHL expressed $\gamma \delta$ TCR and a third expressed CD56 NK marker; indicating a site of intense immunological activity. The techniques described will allow these cell types to be isolated, fully characterised and their physiological functions to be determined. The histologically normal liver contains heterogeneous and diverse IHL with large numbers of CD8 ${ }^{+}, \mathrm{NK}$, NKT and $\gamma \delta^{+}$cells.

Laboratory Investigation (2005) 85, 285-296, advance online publication, 10 January 2005; doi:10.1038/labinvest.3700219
\end{abstract}

Keywords: collagenase; intrahepatic lymphocytes; flow cytometry; cadaveric liver; Immunophenotyping

The liver plays a major role in the development of the immune system during embryonic life and remains an immunologically competent organ after birth. $^{1-6}$ To avoid pathological consequences, mechanisms that reduce unnecessary activation of the immune system are required in the face of continuous exposure to pathogens, toxins, tumour cells and dietary antigens. ${ }^{7}$ The liver has a complex histological structure, which consists primarily of hepatocytes $(70 \%$ of hepatic cellular component), with intrahepatic lymphocytes (IHL) constituting $16-22 \%$ of the remaining nonparenchymal cells $(30 \%) .{ }^{8-10}$ IHL have unusual characteristics and so their study in normal and diseased liver will be an important step towards understanding of the patho-

Correspondence: Dr ND Heaton, FRCS, Liver Transplant Surgical Service, Kings College Hospital, Denmark Hill, London SE5 9RS, UK.

E-mail: Carol.Grimwood@kingshc.nhs.uk

*Current address: Structural Biology, Stanford University School of Medicine, Stanford, CA, USA.

Received 15 April 2004; revised and accepted 2 November 2004; published online 10 January 2005 genesis of liver diseases. Local resident IHL may play a crucial role in avoiding immunological overreactivity, as HLA incompatible allogeneic transplanted liver grafts can survive without the need for immunosuppression. ${ }^{11}$

In human liver, conventional $\mathrm{T}$ lymphocytes that express $\alpha \beta$ T-cell receptors (TCR) are accompanied by $\gamma \delta \mathrm{TCR}^{+} \mathrm{T}$ cells, ${ }^{5} \mathrm{~T}$ cells expressing NK receptors (NKT cells), natural killer (NK) cells ${ }^{5,12}$ and $\mathrm{B}$ cells. ${ }^{5}$

Immunohistochemical study of liver biopsies has facilitated in situ location of IHL to portal tracts and parenchyma and allowed simple phenotyping of lymphoid infiltrates ${ }^{5,13-16}$ but does not provide details about lymphocyte subtypes or their functional attributes. For accurate qualitative and quantitative immunophenotyping, cells must be isolated from fresh tissue. However, special care is required to ensure sufficient cell yields accompanied by satisfactory viability for further analysis.

A variety of methods have been attempted for IHL preparation, including mechanical dissociation ${ }^{17,18}$ 
and/or enzymatic isolation protocols. ${ }^{5,19-21}$ Mechanical methods have yielded very low cell numbers, with low viability and contamination with dead cells and cell debris. Enzymatic methods initially failed to improve cell yields due to long periods of incubation with collagenase. ${ }^{19,22}$ Moreover, the effect of enzymes on the surface markers was not assessed. Proteolytic enzymes may affect the accuracy of lymphocyte phenotyping, since proteolysis of cell surface molecules might perturb their immunological detection and function. ${ }^{17,18}$ Proteolysis may reduce expression of certain lymphocyte surface molecules ${ }^{23}$ or inhibit response to stimulation in vitro. ${ }^{24}$ Furthermore, multiple wash steps and/or overnight incubation may result in further cell loss. Recently, modified procedures for isolation and enrichment of nonparenchymal cells from human livers have been described. ${ }^{5,21}$ These approaches improved yield and viability but resulted in time-dependent enzyme-induced alteration of certain markers. ${ }^{21}$ Hence, further efforts are needed to improve the purity of single-cell suspensions and to ensure that there are sufficient cell yields with acceptable viability for phenotyping and functional analysis.

Using wedge liver biopsies obtained from adult human donors, we compare three different isolation protocols with respect to their effect on cell viability and degree of IHL purity. We have analysed purified cell subpopulations by flow cytometry to give a detailed account of the various IHL subtypes that reside in normal human livers.

\section{Subjects and methods}

All donors included in this study were part of the liver transplantation programme at King's College Hospital. Hospital Ethical Committee approval to collect liver biopsies from cadaveric donors with research consent was granted. Liver retrieval was achieved by a standard operation after in situ perfusion with University of Wisconsin (UW) solution. ${ }^{25}$ UW has no significant effect on lymphocyte viability and functional characteristics ${ }^{21,26}$ and removes the intrasinusoidal lymphocytes that constitute up to $20 \%$ of the hepatic lymphocyte pool, while the resident IHL remain. ${ }^{17}$ Fresh liver biopsies $(\sim 10 \mathrm{~g}$ each) were collected from unused liver segments of 23 donors during liver reduction or splitting at the time of transplantation. Of the donors, $14(61 \%)$ were females and nine $(39 \%)$ males, with a median donor age of 29 years (range 14-59 years). The liver functions were within normal ranges. All liver biopsies were collected in complete RPMI 1640 medium, which contained $2 \mathrm{mM}$ L-glutamine, $25 \mathrm{mM}$ HEPES, $10 \%$ fetal calf serum (FCS), penicillin (50 Us $/ \mathrm{ml}$ ) and streptomycin $(50 \mu \mathrm{g} / \mathrm{ml}) \quad$ (Sigma-Aldrich, Dorset, UK).

\section{Isolation Protocols}

Each donor biopsy was divided into three equal pieces ( $\sim 3 \mathrm{~g}$ each) for isolation of IHL using (a) mechanical, (b) enzymatic digestion, ${ }^{5,21}$ and (c) a modified enzymatic dispersal protocol.

\section{(a) Mechanical method}

Hepatic tissue was dissected on ice, washed twice in Hank's balanced salt solution (HBSS) and scraped extensively with a sterile blade into homogenized suspension in a mixture containing $0.5 \mathrm{mg} / \mathrm{ml}$ collagenase (type IV, $312 \mathrm{U} / \mathrm{mg}$ ) (Sigma-Aldrich), $0.02 \mu \mathrm{g} / \mathrm{ml}$ DNase I, $2 \%$ FCS, $0.6 \%$ bovine serum albumin (BSA) and HBSS at $37^{\circ} \mathrm{C}$. The suspension was passed through a 30- $\mu$ m-nylon mesh filter to remove cell clumps and undissociated tissue. The filtered suspension was centrifuged $(500 \mathrm{~g} ; 10 \mathrm{~min}$; room temperature) and the cell pellet washed twice in HBSS. The final pellet was resuspended in HBSS and hepatocytes removed by differential grade centrifugation (36g; $1 \mathrm{~min}$; room temperature). The resulting supernatant was then centrifuged once again ( $500 \mathrm{~g}$ for $10 \mathrm{~min}$; room temperature) and the pellet was resuspended in complete RPMI 1640 medium. We used $20 \mu \mathrm{l}$ of the fresh cell suspension to assess IHL numbers and viability using ethidium bromide and acridine orange stains (EB/AO) (see below).

\section{(b) Enzymatic digestion method}

Hepatic tissue was washed twice in HBSS and gently chopped with a sterile blade into $\sim 1 \mathrm{~mm}^{3}$ pieces in HBSS-containing collagenase IV $(500 \mathrm{mg} / \mathrm{l}$ (312 U/mg)), DNase I (50 $\mu \mathrm{g} / \mathrm{l})$, FCS $(2 \%)$ and BSA $(0.6 \%)$. The tissue suspension was incubated at $37^{\circ} \mathrm{C}$ for $30 \mathrm{~min}$, and then filtered, washed and centrifuged exactly as above (protocol a.).

\section{(c) Modified enzymatic dispersal protocol}

Hepatic tissue used for this protocol was washed and perfused twice with $\operatorname{HBSS}\left(37^{\circ} \mathrm{C}\right)$ to remove remaining intravascular lymphocytes. The liver tissue was injected with warm HBSS $\left(37^{\circ} \mathrm{C}\right)$ containing collagenase IV (500 mg/l (312 U/mg)), DNase I $(50 \mu \mathrm{g} / \mathrm{l})$, FCS $(2 \%)$ and BSA $(0.6 \%)$ through the blood vessels on the surface whenever possible and directly into the tissue aiming to loosen it. Then, the tissue was gently teased apart with a sterile blade into $\sim 1 \mathrm{~mm}^{3}$ pieces in warm collagenase/HBSS solution $\left(37^{\circ} \mathrm{C}\right)$. The resulting tissue suspension was incubated at $37^{\circ} \mathrm{C}$ for $15 \mathrm{~min}$ with frequent shaking. Following enzymatic digestion, ice-cold HBSS was added immediately to stop the action of the enzymes. The tissue suspension was filtered, washed and centrifuged exactly as before, but with all steps and solutions at $4^{\circ} \mathrm{C}$.

The final cell pellets from each protocol were resuspended in FCS $+10 \%$ dimethyl sulphoxide (DMSO), stored at $-20^{\circ} \mathrm{C}$, then $-80^{\circ} \mathrm{C}$ for $24 \mathrm{~h}$ each, 
followed by storage in liquid nitrogen until required.

The cell number and per cent viability assessment was carried out using a 1:20 dilution of IHL suspension in EB/AO. ${ }^{27}$ Viability was assessed under UV light using a haemocytometer, as viable cells fluoresce green and nonviable cells orange.

Liver biopsies from additional five cadaveric donors were used for mononuclear cell isolation using protocols $\mathrm{a}, \mathrm{b}$ and $\mathrm{c}$. The differential counts of the isolated cell populations were performed on counts of at least 200 cells using Papanicolaoustained cytospin preparations.

\section{Evaluation of the Apoptotic Effect of Collagenase Using Flow Cytometry}

To determine if collagenase has any apoptotic effect on lymphocytes, purified spleen lymphocytes were labelled with flow cytometry TACS ${ }^{\text {TM }}$ Annexin VFITC/propidium iodide-PE (PI-PE) apoptosis detection kit (R\&D Systems, Europe, Oxon, UK). Spleen lymphocytes were isolated from fresh spleen biopsies obtained from three cadaveric donors during multiorgan retrieval. Briefly, Spleen biopsies were mechanically homogenized in spleen preparation medium ( $1 \%$ disodium EDTA in PBS), filtered (30 $\mu \mathrm{m}$ nylon mesh) and washed in HBSS. Monocytes were positively depleted by incubating the spleen cell suspension with carbonyl iron powder (ISP, Manchester, UK) for $10 \mathrm{~min}$ at $37^{\circ} \mathrm{C}$ to allow iron particles phagocytosis by monocytes and then the monocytes were depleted using Dynal magnetic particle concentrator (MPC, Dynal, Merseyside, UK). The mononuclear cell supernatant was collected in clean Falcon ${ }^{\circledR}$ tube and purified by layering the supernatant cell suspension on lymphoprep ${ }^{\mathrm{TM}}$ (Nycomed Amersham, UK) (800g; $\left.20^{\circ} \mathrm{C} ; 20 \mathrm{~min}\right)$. The cloudy buffy coat was removed into a clean tube and washed twice in PBS and pelleted. After resuspending the cell pellet in HBSS, a small aliquot was kept as control. To the remaining cell suspension, a mixture of warm $\operatorname{HBSS}\left(37^{\circ} \mathrm{C}\right)$ containing collagenase IV, (500 mg/l (312 U/mg)), DNase I ( $50 \mu \mathrm{g} / \mathrm{l})$, FCS $(2 \%)$ and BSA $(0.6 \%)$, as that used for IHL isolation, was added. The cell suspension was divided into three aliquots that were incubated at $37^{\circ} \mathrm{C}$ for 20,50 and $90 \mathrm{~min}$. Following enzymatic incubation, ice-cold HBSS was added immediately to the cell suspensions to stop the action of the enzymes and pelleted $\left(500 g ; 4^{\circ} \mathrm{C}\right.$; $10 \mathrm{~min})$. The cell pellets were resuspended, washed and centrifuged twice in ice-cold complete RPMI as mentioned above. The final pellets were resuspended in complete RPMI. Aliquots $(100 \mu \mathrm{l})$ from each cell suspention were incubated with AnnexinV/PI-PE for $15 \mathrm{~min}$ at room temperature according to the manufacturer's instruction. Flow cytometry was performed using a Coulter EPICS-XL I set up for twocolour detection and XL system II software (Beck- man Coulter, High Wycombe, UK). Single Annexin

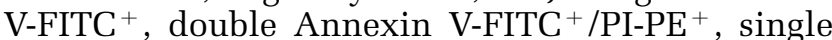
PI-PE ${ }^{+}$and double negative cells staining indicated early apoptotic changes, late apoptotic changes, necrotic cells and viable cells, respectively.

\section{Evaluation of the Apoptotic IHL Component in the Final Cell Product of Isolation Protocols b and c}

Aliquots $(100 \mu \mathrm{l})$ from the final IHL cell suspension isolated from the five additional donor liver specimens using protocols $\mathrm{b}$ and $\mathrm{c}$ were labelled with flow cytometry TACS $^{\mathrm{TM}}$ Annexin V-FITC/PI-PE apoptosis detection kit as mentioned above.

\section{Purification Protocols}

A total of 10 donor IHL cell suspentions isolated using protocol c were retrieved from liquid nitrogen, left to thaw on ice and washed twice in cold complete RPMI 1640 medium. Cells were pelleted (500g; $4^{\circ} \mathrm{C} ; 10 \mathrm{~min}$ ) and resuspended in FACS buffer (PBS/BSA/sodium azide). Cell count and viability were evaluated before and after purification.

\section{(1) Purification by simple filtration (Group I)}

The filtrate was used directly for FACS analysis without any further purification.

\section{(2) Filtration and positive selection of IHL using} immunomagnetic microbeads

Positive selection was used to obtain a cell suspension free of parenchymal and other non-IHL, dead cells and cell debris.

\section{(a) Using anti-CD2 beads (Group II)}

CD2 costimulatory molecule is expressed on hepatic $\mathrm{T}$ and NKT cells.,12 Anti-CD2 immunomagnetic microbeads (Dynal, Merseyside, UK: $6.6 \times 10^{8}$ beads $/ \mathrm{ml}$ ) and releasing buffer were used according to the manufacturer's instructions.

\section{(b) Using anti-CD56 beads (Group III)}

CD56 is expressed on all hepatic NK and NKT cells. ${ }^{5,12}$ MACS anti-CD56 microbeads and separation column (Miltenyi Biotec, Surrey, UK; mouse IgG2b, Clone: NCAM 16.2) were used according to the manufacturer's instructions. Briefly, the magnetically labelled $\mathrm{CD}^{2} 6^{+}$cells were retained in the column while the unlabelled CD56 ${ }^{-}$cells continued through. After removal of the column from the magnetic field, the magnetically retained CD56 ${ }^{+}$cells were eluted as a positively selected cell fraction.

\section{Evaluation of Purification Protocols Using Flow Cytometry}

Purified IHL populations were stained using CY5-conjugated CD45-specific monoclonal antibody 
(mAb) (CD45-CY5 (j.33 clone)). Cells from Group I and Group II were counterstained with mAb conjugated with fluorescein isothiocyanate (FITC) or phycoerythrin (PE) flourochromes that included CD3-PE or CD3-FITC (UCHT1), CD19-PE (HD37), CD14-FITC (TÜK4), CD4-FITC (13B8.2), CD8-PE (B9.11) and CD161-PE (191B8) (Beckman Coulter, Buckinghamshire, UK and BD Biosciences, Oxford, UK). The cells from Group III were counterstained with CD3-PE or CD3-FITC, CD19-PE, CD14-FITC or CD161-PE.

IHL from Groups I-III were gated according to the forward and side light scatter properties of normal lymphocytes and also by CD45-CY5 fluorescence.

\section{Phenotyping of Intrahepatic Lymphocytes}

In all, $100 \mu \mathrm{l}$ aliquots of IHL suspension that were isolated from 19 donor livers using the optimised protocol were stained with combinations of CD45-CY5, CD3-FITC, CD3-PE, CD19-PE, CD14-FITC, CD4-PE, CD4-FITC (13B8.2), CD8-PE, CD8-FITC, CD16-PE, CD56-PE (N901 (NKH1)), CD161-PE (191B8), $\alpha \beta$ TCR-PE (BMA 031), $\gamma \delta$ TCRPE (IMMU510), TCRV $\alpha 24$ (C15) and CD45RO-PE (UCHL1) (Beckman Coulter, Bucks, UK and BD Biosciences, Oxford, UK). The lymphocyte populations were identified using CD45-CY5 fluorescence gating as above.

IHL phenotyping was performed using a Coulter EPICS-XL I set up for three-colour detection and XL system II software (Beckman Coulter, High Wycombe UK).

Flow cytometry data were analysed using WinMDI software and statistical analysis performed using SPSS-version 9.0. Nonparametric test (MannWhitney U-test) for independent samples was used to test differences among study groups.

\section{Results}

\section{Isolation and Purification Methods}

The mechanical method yielded low cell numbers (mean; $0.8 \times 10^{6} / 100 \mathrm{mg}$ ) with a mean $39 \%$ viability (ie viable: dead cell ratio $\sim 1: 3$ ). The original enzymatic digestion protocol improved yield and viability $\left(1.3 \times 10^{6} / 100 \mathrm{mg}\right.$ and $86.4 \%$ viability $)$, while the modified enzymatic digestion protocol had a lower yield, but the highest viability $\left(1.16 \times 10^{6} / 100 \mathrm{mg}\right.$ (range $\left.0.6-1.6 \times 10^{6}\right)$ and $92.6 \%$ viability) (Table 1). Papanicolaou-stained cytospin preparations of the cell populations isolated using protocols a, b and c after purification with simple filtration, revealed that the lymphocyte population accounted for $84 \pm 2.8 \%$ (range $81.5-88.5 \%$ ) for protocol b compared with $85.5 \pm 3.1 \%$ (range $81-$ $89 \%)$ for protocol c $(P>0.05)$, with $16 \pm 2.7 \%$ (range $11.5-18.5 \%$ ) and $14.5 \pm 3.5 \%$ (range $11-19 \%$ ) hepatocytes and nonparenchymal (liver sinusoidal endothelial cells, dendritic cells, Kupffer cells and polymorphonuclear cells), respectively. The morphological characteristics of the cell population isolated using the mechanical protocol showed less parenchymal and nonparenchymal cells with high proportion of degraded cells, nuclei and cell debris (Figure 1).

The incubation of spleen lymphocytes with collagenase for different periods of time revealed no significant difference between 20 min exposure and the control with minimal apoptotic changes with $2.4 \%$ Annexin- $\mathrm{V}^{+}$and $2.3 \%$ Annexin- $\mathrm{V}^{+} / \mathrm{PI}^{+}$ compared to 1.2 and $0.7 \%$ for control, respectively. Significant early and late apoptotic changes were observed for 90 min incubation time as $9.5 \%$ of the cell population were Annexin- $\mathrm{V}^{+}$and $9.8 \%$ were Annexin- $\mathrm{V}^{+} \mathrm{PI}^{+}$compared to 2.8 and $4.4 \%$ for $50 \mathrm{~min}$ incubation time and 2.4 and $2.3 \%$ for 20 min incubation time (Figure 2).

Table 1 Time of exposure to collagenase, cell yields and viability of IHL with different isolation techniques

\begin{tabular}{|c|c|c|c|}
\hline & \multicolumn{3}{|c|}{ Isolation protocols } \\
\hline & Mechanical $(\mathrm{n}=23)$ & $\begin{array}{l}\text { Enzymatic dispersal } \\
\qquad(\mathrm{n}=23)\end{array}$ & $\begin{array}{l}\text { Modified enzymatic } \\
\text { dispersal }(\mathrm{n}=23)\end{array}$ \\
\hline Total time of protocol (min) & $40-50$ & $60-70$ & $60-70$ \\
\hline Dissection in collagenase & $7-10$ & 5 & 5 \\
\hline Incubation with collagenase & 0 & 30 & 15 \\
\hline Time in collagenase after incubation & 15 & 15 & $0^{\mathrm{a}}$ \\
\hline Total time of collagenase exposure & $20-25$ & 50 & 20 \\
\hline Cell yield/100 mg $\mathrm{mb}^{\mathrm{b}}$ & $0.8 \times 10^{6}\left(0.2-1.2 \times 10^{6}\right)$ & $1.3 \times 10^{6}\left(0.9-3.2 \times 10^{6}\right)$ & $1.16 \times 10^{6}\left(0.6-1.6 \times 10^{6}\right)$ \\
\hline Viability \%mean (range) ${ }^{\mathrm{b}}$ & $39(12-68)$ & $86.4(68-92)$ & $95.4(74-98)$ \\
\hline MNC purity (\%mean \pm (range)) & $62.6 \pm 10.6(48-72.5)$ & $84+2.8(81.5-88.5 \%)$ & $85.5 \pm 3.0 \%(81-89 \%)$ \\
\hline $\begin{array}{l}\text { Parenchymal and nonparenchymal cells and cell } \\
\text { debris (\% mean } \pm \text { (range)) }\end{array}$ & $37.4 \pm 10.5(27.5-52)^{\mathrm{c}}$ & $16 \pm 2.7(11.5-18.5 \%)$ & $14.5 \pm 3.5(11-19 \%)$ \\
\hline
\end{tabular}



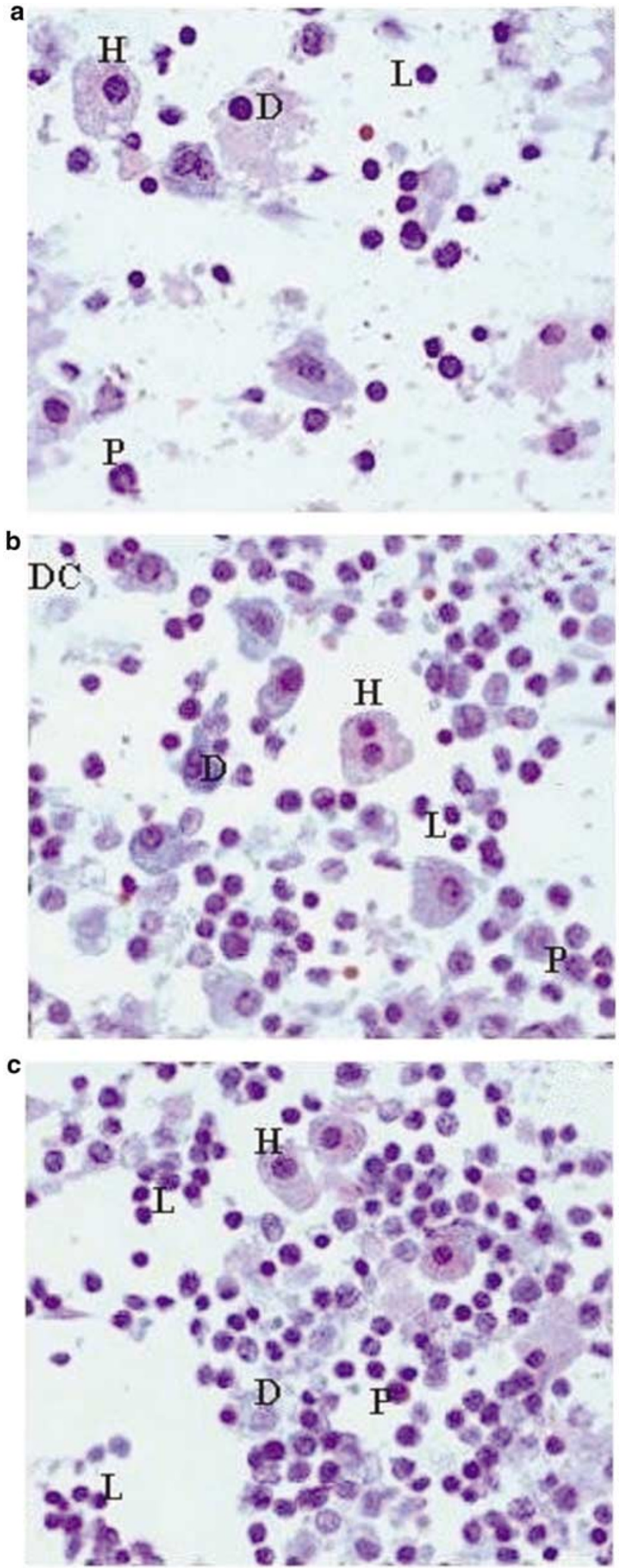

Figure 1 The morphology of liver cell products isolated using protocols a, b and c. Papanicolaou-stained cytospin preparations comparing the morphology of intrahepatic mononuclear cells isolated using mechanical (a), enzymatic digestion (b) and modified enzymatic dispersal (c) protocols (original magnification $\times 400)$. H; hepatocytes, L; lymphocytes, DC; dendritic cells, $\mathrm{P}$; polymorphonuclear cells, D; degraded cells.
Small difference was found in apoptotic IHL population isolated from UW-perfused donor liver specimens using the enzymatic dispersal and the modified enzymatic dispersal protocol. Early (Annexin- $\mathrm{V}^{+}$) and late apoptotic (Annexin- $\mathrm{V}^{+} / \mathrm{PI}^{+}$) IHL were $2.6 \%$ (range $0.5-4.1 \%$ ) and $3.8 \%$ (range $0.7-5.8 \%$ ) for the enzymatic dispersal protocol compared to $2.3 \%$ (range $0.5-3.3 \%$ ) and $3.6 \%$ (range $0.5-4.7 \%)$ for the modified protocol, respectively. While dead or necrotic cells $\left(\mathrm{PI}^{+}\right)$accounted for $7.7 \%$ (range $2.6-9.1 \%$ ) for the enzymatic dispersal protocol compared to $2.3 \%$ (range $0.3-3.1 \%$ ) for the modified protocol (Figure 3).

The use of anti-CD2 and anti-CD56 immunomagnetic microbeads enabled further purification of the IHL population (Table 2). There were less than $5 \%$ dead cells compared with $12 \%$ without beads, and less contamination with CD14 ${ }^{+}$cells; 3.9, and 0.5\%, respectively, compared to $15.2 \%$ without beads. Using CD45-CY5 to gate IHL in addition to microbeads isolation resulted in higher estimates of CD3, CD4, CD8 and CD161 positive cells and less contamination with other non-IHL cells (Figure 4). Indicating that these populations had previously been under estimated.

\section{Phenotyping of Intrahepatic Lymphocytes in Donor Livers}

Intrahepatic T lymphocytes $\left(C D 3^{+}\right)$

Phenotype characterisation of IHL was performed using three-colour FACS analysis on freshly isolated IHL from 19 adult donor livers. The majority of the IHL population expressed CD3, with a mean value of $78.2 \%$ (Table 3 ). CD4 ${ }^{+}$accounted for an average of $29.6 \%$ of the CD3 ${ }^{+}$IHL and $43.9 \%$ expressed CD8 coreceptor, with a mean CD4:CD8 ratio of 0.7 (Table 3). A double-positive (CD8 ${ }^{+} \mathrm{CD} 4^{+}$) subset accounted for $2.7 \%$ of $\mathrm{CD}^{+}, 10.2 \%$ of $\mathrm{CD} 4^{+}$and $6.7 \%$ of the total $\mathrm{CD}^{+}$IHL. A double-negative $\left(\mathrm{CD} 8^{-} \mathrm{CD} 4^{-}\right)$ subset accounted for an average $22.7 \%$ of $\mathrm{CD}^{+}$ IHL (Table 4, Figure 5).

The majority of $\mathrm{CD}^{+}$IHL expressed $\alpha \beta \mathrm{TCR}$ (mean $80.8 \%$ ) and $\gamma \delta$ TCR was expressed on $18.8 \%$ (Table 4). Most CD4 ${ }^{+}$IHL expressed $\alpha \beta$ TCR (mean $81.7 \%$ ) while $15.9 \%$ expressed $\gamma \delta$. The majority of $\mathrm{CD}^{+}$IHL expressed $\alpha \beta$ TCR (mean $83.7 \%$ ) while $18.4 \%$ expressed $\gamma \delta$ TCR. CD45RO was expressed on an average $66 \%$ of $\mathrm{CD}^{+}{ }^{+}$and $35.2 \%$ of $\mathrm{CD}^{+}$IHL (Table 4).

NKT cells $\left(\mathrm{CD}^{+}{ }^{+} \mathrm{CD} 56^{+}, \mathrm{CD}^{+}{ }^{+} \mathrm{CD} 161^{+} \mathrm{CD}^{+} 6^{+}\right.$and $C D 3^{+} \mathrm{V} \alpha 24^{+}$)

Three-colour FACS analysis using CD45CY5 fluorescence gating of freshly isolated and filtration purified IHL revealed that approximately one-third of IHL lymphocytes expressed the CD56 NK marker (range 14.6-43.8\%; Table 3). $\mathrm{T}$ cells that express CD56 $\left(\mathrm{CD} 3{ }^{+} \mathrm{CD}^{+} 6^{+}\right)$accounted for $23.1 \%$ of the $\mathrm{CD}^{+}$ population and $15.9 \%$ of the total IHL (Table 4 ). 

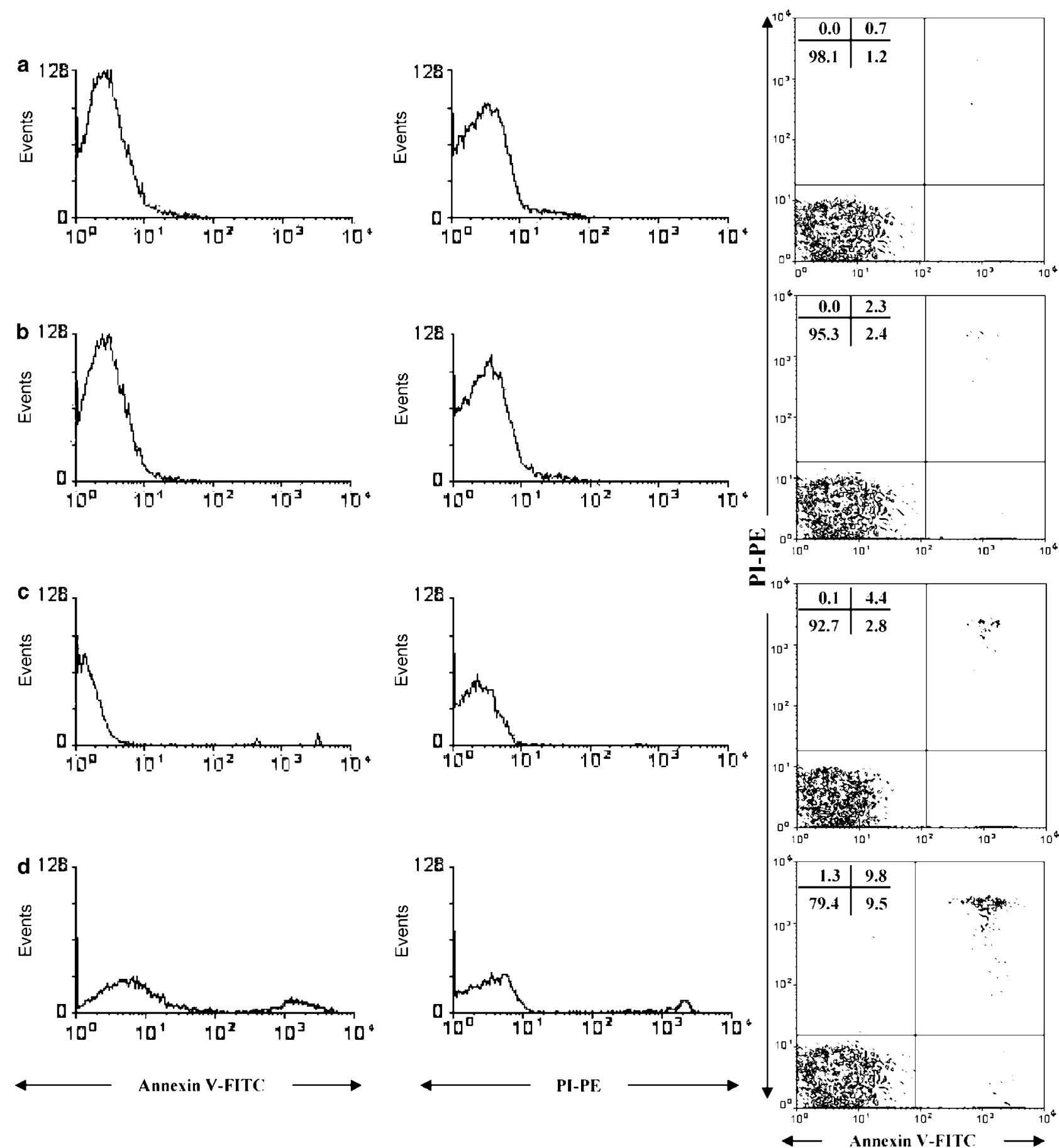

Figure 2 The apoptotic effect of collagenase on spleen lymphocytes. Flow cytometry histogram and contour plots demonstrating the apoptotic effect of collagenase on spleen lymphocytes comparing the incubation of collagenase with spleen lymphocytes for different periods of time. In comparison to control (a) there is minimal early (Annexin- $\mathrm{V}^{+}$) and late apoptotic changes $\left(\right.$Annexin- $\mathrm{V}^{+} \mathrm{PI}^{+}$) after $20 \mathrm{~min}(\mathbf{b})$ and $50 \mathrm{~min}$ (c) incubation. There is increasing apoptotic changes with increased incubation time to $90 \mathrm{~min}$ (d). The values inside represent the mean proportions of sorted cells.

Anti-CD56 immunomagnetic beads followed by CD45-CY5 fluorescence gating showed that $\mathrm{CD} 3{ }^{+} \mathrm{CD}_{56}{ }^{+}$accounted for an average $44.7 \%$ of the $\mathrm{CD}^{+} 6^{+}$IHL population. $\mathrm{CD} 3{ }^{+} \mathrm{CD} 161^{+} \mathrm{CD} 56^{+}$ accounted for $10.7 \%$ of the total IHL, $69.8 \%$ of $\mathrm{CD}^{+}{ }^{+} \mathrm{CD}_{56}{ }^{+}$IHL and $15.9 \%$ of the $\mathrm{CD}^{+}$IHL population (Table 3). $\mathrm{CD}^{+} \alpha 24^{+}$accounted for $1.3 \%$ of the $\mathrm{CD}^{+}$IHL population.

NK Cells $\left(C D 3^{-} C D 56^{+}\right)$

This analysis revealed that the human liver contains a proportion of IHL bearing the NK phenotype 


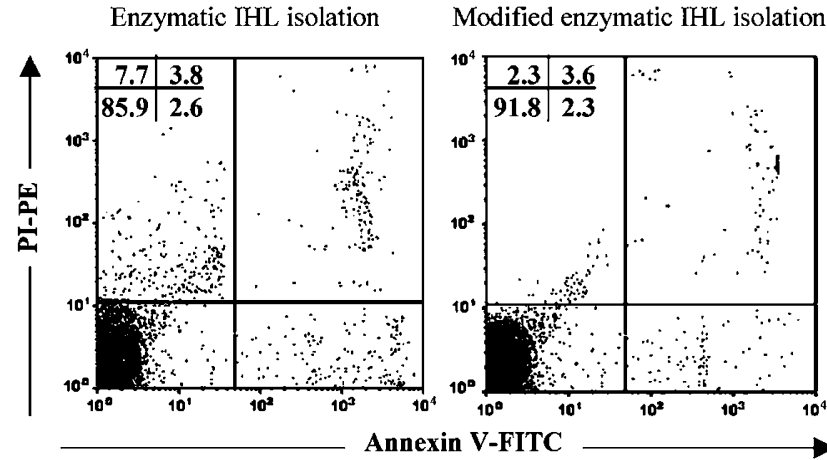

Figure 3 Isolation of the apoptotic IHL component. Flow cytometry contour plots demonstrating the apoptotic IHL component in the cell population isolated using the enzymatic digestion (left) and the enzymatic dispersal (right) protocols. Both protocols isolated approximately similar small proportions of apoptotic cells represented by Annexin- $\mathrm{V}^{+}$and Annexin- $\mathrm{V}^{+} \mathrm{PI}^{+}$cells with slightly higher proportion for the enzymatic digestion protocol with more dead or necrotic cells $\left(\mathrm{PI}^{+}\right)$than the modified protocol. The values inside represent the mean proportion of sorted cells.

(mean $19.7 \%$ of the total IHL; Table 3). NK $\left(\mathrm{CD}^{-} \mathrm{CD}^{-} 6^{+}\right)$accounted an average $55.3 \%$ of the total $\mathrm{CD}^{+}{ }^{+}$IHL population. $\mathrm{CD}^{-} \mathrm{CD}^{-} 161^{+} \mathrm{CD}^{+} 6^{+}$ accounted for $58.8 \%$ of NK IHL.

\section{Discussion}

In this study, a multistep protocol for IHL isolation, purification and FACS analysis has been devised and compared with published protocols for mechanical dissociation ${ }^{5,17,18}$ and enzymatic dispersal..$^{5,19-21}$ The mechanical protocol resulted in poor viability, which was improved by enzymatic dispersal. However, the modified protocol yielded the highest percentage of viable cells. This may be ascribed to less mechanical disruption facilitated by injecting warm HBSS $\left(37^{\circ} \mathrm{C}\right)$ containing collagenase, short exposure to collagenase and cold centrifugation compared to the original enzymatic dispersal method. While the original dispersal protocol isolated slightly higher proportions of apoptotic IHL, higher necrotic and dead cell proportions compared with the modified protocol. The low proportion of apoptotic cells isolated using both protocols might be ascribed to the wash out of intrasinusoidal recruited apoptotic lymphocytes during liver retrieval and back table UW solution perfusion. The incubation of splenic lymphocytes with collagenase revealed increasing apoptotic changes with more than 1-h incubation, while small difference was found between 20 and 50 min incubation. However, several reports showed that long exposure to collagenase might also affect the accuracy of subsequent phenotyping. ${ }^{17,18,23,21}$

The optimised isolation protocol yielded sufficient pure and viable single cells for flow cytometry. However, the isolated cell population using different protocols including the modified dispersal protocol contained high numbers of parenchymal and nonparenchymal cells. Additionally, cryopreservation, thawing and frequent washing steps may lead to more cell death and hence cell debris. Therefore, we attempted further purification protocols that included simple filtration and positive selection for lymphocyte subsets using magnetic microbeads. The combined purification protocols resulted in highly viable single-cell suspensions. The optimised isolation protocol has been applied successfully for immune phenotyping in small size as well as percutaneous liver biopsies from patients with hepatitis $\mathrm{C}$ and alcohol-related chronic liver diseases and extrahepatic biliary atresia that has been and being carried out in our laboratory.

To improve the accuracy in estimating IHL subsets during flow cytometry, we have evaluated fluorescence gating by labelling the cells with a mAb specific for CD45 (the common leukocyte antigen). Using cells isolated with the optimised protocol, CD45-CY5 gating resulted higher estimates of IHL and less contamination with other nonparenchymal cells than simple light scatter parameters. The use of fluorescence gating could eliminate the need for purification protocols that may lead to selective subpopulation loss. Additionally, fluorescence gat-

Table 2 Implications of different purification/selection techniques

\begin{tabular}{|c|c|c|c|c|c|c|c|}
\hline \multirow[t]{2}{*}{ Protocol } & \multirow[t]{2}{*}{ Viability (\% mean) } & \multicolumn{6}{|c|}{$\% \operatorname{Mean} \pm s . d .^{\mathrm{a}}$} \\
\hline & & $C D 19^{+}$ & $C D 14^{+}$ & $C D 3^{+}$ & $C D 4^{+}$ & $C D 8^{+}$ & $C D 161^{+}$ \\
\hline (1) Filtration & 88.1 & $7.3 \pm 0.3$ & $15.2 \pm 0.5$ & $36.8 \pm 1.8$ & $7.2 \pm 4.7$ & $19.2 \pm 4.6$ & $18.7 \pm 5.3$ \\
\hline (2) Filtration and fluorescence gating ${ }^{\mathrm{b}}$ & 88.1 & $6.6 \pm 0.2$ & $5.8 \pm 0.6$ & $50.0 \pm 2.5$ & $13.4 \pm 7.3$ & $25.1 \pm 3.8$ & $25.2 \pm 2.7$ \\
\hline (3) CD2 beads and fluorescence gating & 95.4 & $0.8 \pm 0.4$ & $4.2 \pm 0.5$ & $77.5 \pm 4.8$ & $18.8 \pm 5.6$ & $36.4 \pm 8.7$ & $18 \pm 3.3$ \\
\hline (4) CD56 beads and fluorescence gating & 97.3 & $0.3 \pm 0.081$ & $0.5 \pm 0.1$ & - & - & - & $52.6 \pm 2.8$ \\
\hline
\end{tabular}

${ }^{\mathrm{a}}$ Values represent the percentage of each subset out of the gated population.

${ }^{b}$ Light scatter gating was used to sort cells in protocol 1 and fluorescence gating (CD45-CY5) to sort cells in the other three protocols.

Mann-Whitney $U$-test was used to test the difference between different protocols. The difference was statistically significant between prtocol 1 and 2 in all subsets; and significant between protocol 1 and 2 vs 3 in CD19 ${ }^{+}, \mathrm{CD}^{4} 4^{+}, \mathrm{CD}^{+}{ }^{+} \mathrm{CD}^{+}$cells $(P<0.01)$.

The difference was significant between protocol 1 and 4 in tested subsets; and between 2 and 4 protocols CD19 ${ }^{+}$and CD14 ${ }^{+}$cell contamination. CD $161^{+}$subsets are not compared in protocol 1 and 2 vs 3 or 4 due to the selective nature of the magnetic beads in protocols 3 and 4 .

- Not tested. 

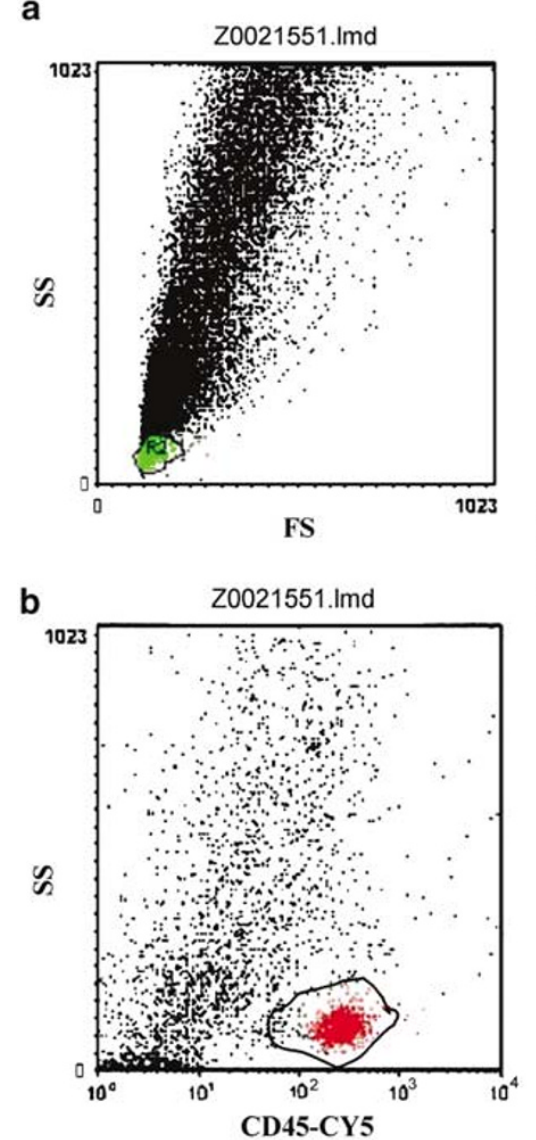
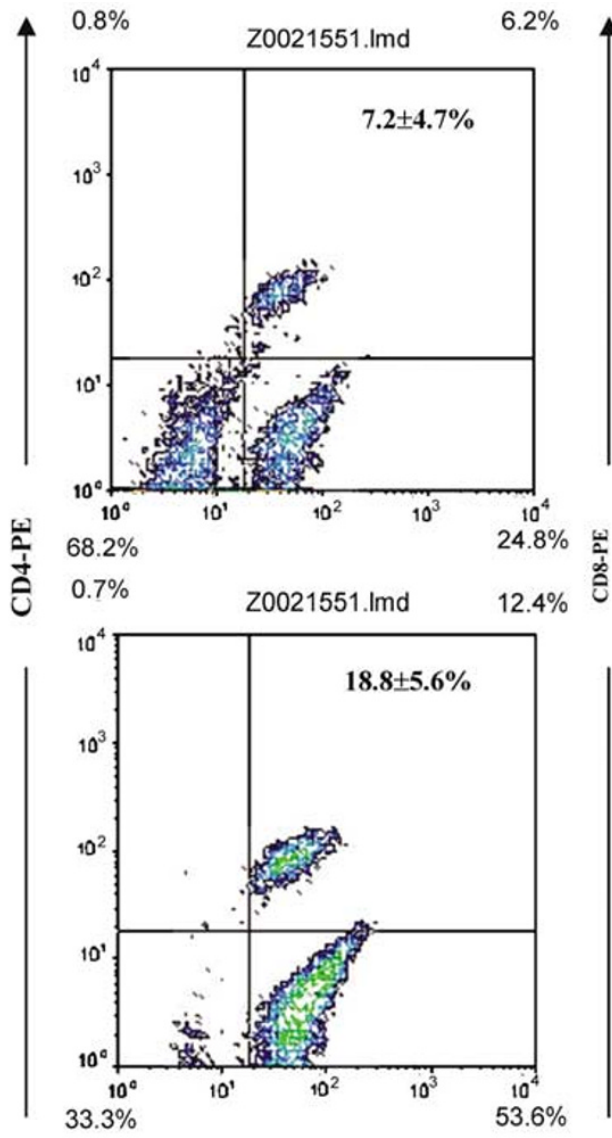
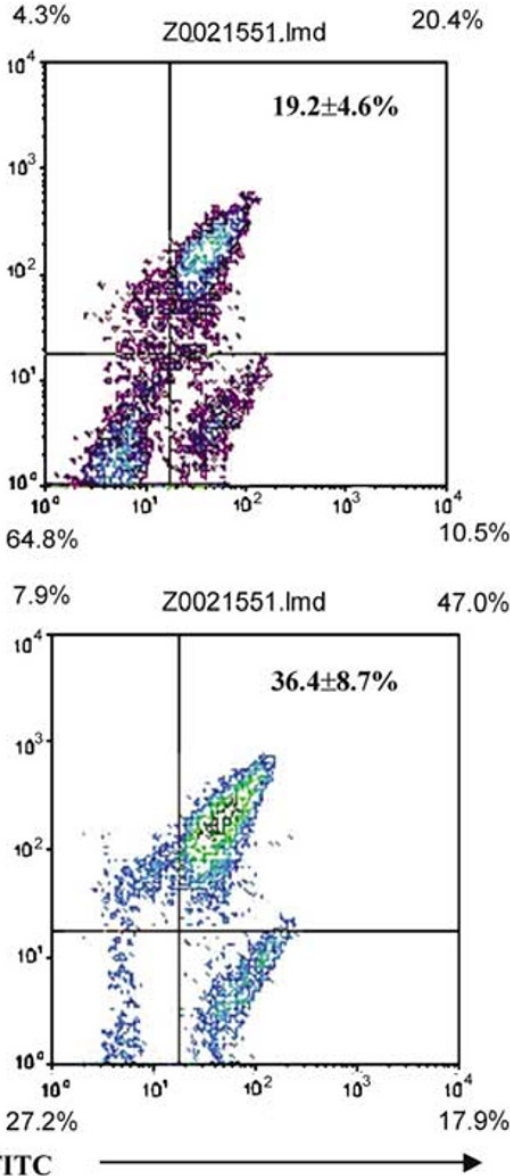

Figure 4 Flow cytometry plots demonstrating the differences in CD4 ${ }^{+}$IHL and CD8 ${ }^{+}$IHL proportions in the same cell suspension using different purification and cell sorting protocols. (a) Simple filtration protocol and cell sorting (gate) using the traditional light scatter (forward- and side-scatter) parameters (lymphogate-green), and two-colour FACS analysis. (b) Purification protocol using anti-CD2 immunomagnetic beads and cell sorting (gate) using fluorescence gating (anti-CD45-CY5-red) and three-colour FACS analysis. The values outside and inside represent the FACS reading of cell subsets in the studied sample and the mean values of CD4 ${ }^{+}$and CD8 ${ }^{+}$cells in all samples, respectively. These plots show that $\mathrm{CD}^{+}{ }^{+}$and $\mathrm{CD} 8^{+}$IHL populations are underestimated in protocol (a) compared to (b) $(P<0.01)$.

Table 3 IHL subsets in donors

\begin{tabular}{|c|c|}
\hline IHL subsets & $\%$ Mean \pm s.d. $($ range $)(\mathrm{n}=19)$ \\
\hline Total T CD3 ${ }^{+}$ & $78.2 \pm 11(46.8-86.1)$ \\
\hline Total NK CD3-CD56 ${ }^{+}$ & $19.7 \pm 6.4(10.7-30.3)$ \\
\hline Total CD3 ${ }^{+} \mathrm{CD} 6^{+}$ & $15.9 \pm 7(7.5-28.2)$ \\
\hline Total CD56 ${ }^{+}$ & $35.6 \pm 11.7(18.2-51.6)$ \\
\hline $\mathrm{CD}^{-}{ }^{-\mathrm{CD}_{5}}{ }^{+} / \mathrm{CD} 56$ & $55.3 \pm 15.5(21.3-66.2)$ \\
\hline $\mathrm{CD}^{+}{ }^{\mathrm{CD}} 56^{+} / \mathrm{CD} 56$ & $44.7 \pm 15.5(33.8-78.7)$ \\
\hline Total CD3 ${ }^{-} \mathrm{CD}_{161^{+} \mathrm{CD} 56^{+}}$ & $11.6 \pm 3.7(6.2-17.6)$ \\
\hline Total CD $3^{+} \mathrm{CD} 161^{+} \mathrm{CD}^{2} 6^{+}$ & $10.7 \pm 4.8(5.2-19.4)$ \\
\hline Total $\mathrm{CD}^{+}{ }^{+} \mathrm{V} \alpha 24^{+}$ & $1.0 \pm 0.6(0.9-2.0)$ \\
\hline
\end{tabular}

$\mathrm{CD}^{+}{ }^{\mathrm{CD}} 56^{+}, \mathrm{CD}^{+} \mathrm{CD} 161^{+} \mathrm{CD}^{2} 6^{+}$and $\mathrm{CD} 3^{+} \mathrm{V} \alpha 24^{+}$are considered NKT cells. ${ }^{35}$

ing reduces the technical challenge, which in turn reduces time and cost. ${ }^{28}$

We demonstrated that histologically normal adult human liver contains high numbers of IHL that are charaterised by their heterogeneity and distinctive phenotypes. $\mathrm{CD}^{+}$IHL were the predominant population with $\mathrm{CD} 4^{+} / \mathrm{CD} 8^{+}$ratio $1: 1.7$, which is a reversal of peripheral blood lymphocytes, where $\mathrm{CD} 4{ }^{+}$T cells are the predominant subpopulation. ${ }^{5,29}$ Double-positive $\left(\mathrm{CD}^{+}{ }^{+} \mathrm{CD} 4^{+}\right)$and double-negative $\left(\mathrm{CD} 8^{-} \mathrm{CD} 4^{-}\right)$subsets constituted proportions of $\mathrm{CD}^{+}$IHL population. CD45RO (effector/memory phenotype) was expressed on the majority of CD4 ${ }^{+}$ IHL. While these results are generally consistent with previous reports, ${ }^{5,19}$ the detailed proportions of these subpopulations are different. $\mathrm{CD}^{+}$and $\mathrm{CD}^{-} \mathrm{CD}^{-} \mathrm{T}$ cells were higher and $\mathrm{CD}^{+} \mathrm{T}$ cells were lower in this study compared with one study, ${ }^{5}$ while CD3 ${ }^{+}$cells were higher compared to another study. ${ }^{19}$ Such cells, represent a constitutive population of the liver and not specific recruitment into the livers of brain-stem dead donors. Thus, the differences could be ascribed to the quality of donor liver, variations in IHL isolation protocols and the fluorescent gating used during flow cytometry.

While the vast majority of $\mathrm{T}$ cells present in the liver express $\alpha \beta$ TCR, we have shown that the histologically normal human liver contains high proportions of $\gamma \delta^{+}$T cells (18.8\%). The peripheral 

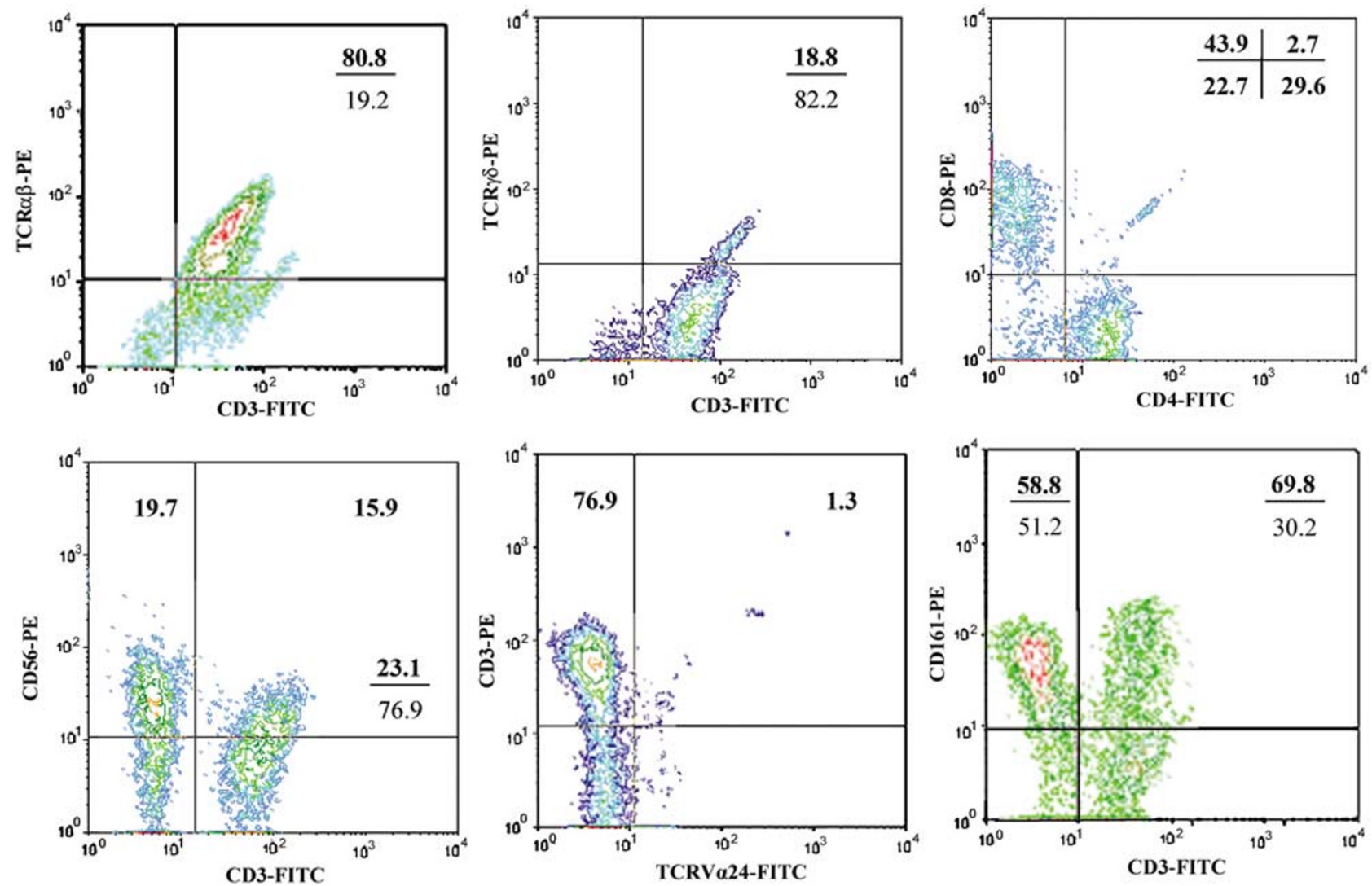

Figure 5 Intrahepatic Lymphocyte subsets. Flow cytometry contour plots show the diversity of IHL isolated from histologically normal donor liver specimens. The values inside represent the mean values of sorted subsets. The majority of CD3 ${ }^{+}$IHL express $\alpha \beta$ TCR (ab) with about one-fifth express $\gamma \delta$ TCR (gd). CD8 ${ }^{+}$IHL is the predominant population. The donor liver contains IHL populations that express $\mathrm{CD}^{+} \mathrm{CD}^{+}$and $\mathrm{CD}^{-} \mathrm{CD}^{-}$phenotype. Approximately, one-third of IHL express CD56 marker. The donor liver contains large populations of NK cells CD3 ${ }^{-} \mathrm{CD} 56^{+}$IHL and NKT cells $\left(\mathrm{CD} 3^{+} \mathrm{CD}^{+} 6^{+}, \mathrm{CD} 3^{+} \mathrm{V} \alpha 24^{+}\right.$and $\mathrm{CD} 3^{+} \mathrm{CD} 161^{+}$). The last FACS plot shows the expression of CD161 by CD56 ${ }^{+}$IHL selected using anti-CD56 immunomagnetic beads. The majority of NK and CD ${ }^{+}$CD56 ${ }^{+}$IHL express CD161 marker.

circulation, spleen and lymph nodes of healthy adults contain $1-10 \%$ of T cells expressing $\gamma \delta$ TCR. ${ }^{30}$ Thus, in agreement with previous findings the human liver is an important location for $\gamma \delta$ cells, with a higher concentration only found in the intestine. ${ }^{5}$ In contrast to $\alpha \beta \mathrm{TCR}^{+} \mathrm{T}^{-}$cells, which are selected in the thymus, the $\gamma \delta$ T cell repertoire may be generated and selected extrathymically. ${ }^{31} \gamma \delta^{+} \mathrm{T}$ cells have an immunoregulatory role through release of IFN $\gamma, \mathrm{TNF} \alpha$ and growth factors, ${ }^{30,32}$ can mediate non-MHC-restricted cytolytic activity in a similar manner to $\mathrm{NK}^{33}$ and play an important role in eliminating damaged or infected epithelial cells. ${ }^{30}$ The presence of large numbers of $\gamma \delta \mathrm{T}$ cells in the liver may suggest that, like epithelial $\gamma \delta^{+}$T cells, ${ }^{34}$ they are involved in the elimination of parasites and microbes or virally infected and tumour cells. Intrahepatic $\gamma \delta$ T cells may also have a role in repair and regeneration in the liver through secretion of growth factors. ${ }^{6}$

In addition to conventional lymphocytes, normal human livers were populated with $\mathrm{T}$ cells expressing the NK receptor CD56 $\left(\mathrm{CD}^{+}{ }^{+} \mathrm{CD} 56^{+}\right)$with a proportion of them also expressing CD161
$\left(\mathrm{CD} 3{ }^{+} \mathrm{CD} 161^{+} \mathrm{CD} 6^{+}\right)$. There was also a small population $(1.2-2.5 \%)$ of $\mathrm{T}$ cells with $\mathrm{CD}^{+}$ $\mathrm{CD}^{2} 6^{+} \mathrm{V} \alpha 24^{+}$phenotype, consistent with a previous report by Norris et al. ${ }^{12}$ These $\mathrm{CD} 3{ }^{+} \mathrm{CD} 56^{+}$cells may also express KIRs and either $\alpha \beta$ or $\gamma \delta$ TCR $^{12}$ and have been classified as either $\mathrm{NT}^{35}$ or NKT cells. ${ }^{36}$ Although their precise phenotypic composition and identity compared to their murine counterparts remain controversial, it is clear that these cells have an important physiological role as they are able to kill or induce killing of human tumour cell lines and control hepatitis $\mathrm{B}$ and $\mathrm{C}$ virus and malaria infection. ${ }^{36,37}$ Furthermore, NKT cells may be activated by microbial antigens and may have a role in autoimmune liver diseases pathogenesis. ${ }^{37}$

We showed that the human liver contains a proportion of $\mathrm{NK}$ cells $\left(\mathrm{CD}^{-} \mathrm{CD}^{-} 6^{+} ; 20 \%\right.$ ), the majority of them also expressing CD161, which is the human equivalent of mouse NK1.1. Estimates of the NK proportion in normal human liver have varied, ${ }^{12,38,39}$ which is most likely due to the differences in isolation techniques, enzyme exposure times or even the quality of the original livers 
Table 4 IHL subsets in donors

\begin{tabular}{|c|c|}
\hline IHL subsets & $\%$ Mean \pm s.d. (range) $(\mathrm{n}=19)$ \\
\hline \multicolumn{2}{|l|}{$C D 3^{+}$population } \\
\hline $\mathrm{CD}^{+}{ }^{+} \mathrm{CD}^{+}$ & $29.6 \pm 7.6(23-47.4)$ \\
\hline $\mathrm{CD}^{+}{ }^{\mathrm{CD}} 3^{+}$ & $43.9 \pm 8.5(37.9-61.8)$ \\
\hline $\mathrm{CD}^{+}{ }^{\mathrm{CD}} 8^{+}$ & $2.7 \pm 3.4(0.3-10.5)$ \\
\hline $\mathrm{CD}^{-}{ }^{\mathrm{CD}} 8^{-}$ & $22.7 \pm(9.8-38.6)$ \\
\hline $\mathrm{CD}^{+}: \mathrm{CD}^{+}$ & $0.7 \pm 0.2(0.5-1.3)$ \\
\hline$\alpha \beta \mathrm{TCR}$ & $80.8 \pm 10.3(58.4-92.9)$ \\
\hline$\gamma \delta \mathrm{TCR}$ & $18.8 \pm 12.9(3.1-42.8)$ \\
\hline $\mathrm{CD}^{+}{ }^{+} \mathrm{CD} 56^{-}$ & $76.9 \pm 8.6(62.4-87.8)$ \\
\hline $\mathrm{CD}^{+}{ }^{+} \mathrm{CD} 56^{+}$ & $23.1 \pm 8.6(12.2-37.7)$ \\
\hline $\mathrm{CD}^{+}{ }^{\mathrm{CD}} 161^{+} \mathrm{CD}^{2} 6^{+}$ & $15.9 \pm 5.9(8.4-26)$ \\
\hline $\mathrm{CD}^{+} \mathrm{V} \alpha 24^{+}$ & $1.3 \pm 0.8(1.2-2.5)$ \\
\hline \multicolumn{2}{|l|}{$C D 4^{+}$population } \\
\hline $\mathrm{CD}^{+}{ }^{+} \mathrm{CD} 8^{+}$ & $10.2 \pm 9.7(2.7-30.5)$ \\
\hline$\alpha \beta$ TCR & $81.7 \pm 7.1(70.4-93.8)$ \\
\hline$\gamma \delta \mathrm{TCR}$ & $15.9 \pm 11(1.01-30.1)$ \\
\hline $\mathrm{CD}^{\prime} 5 \mathrm{RO}^{+}$ & $66 \pm 11(38.4-73)$ \\
\hline \multicolumn{2}{|l|}{$C D 8^{+}$population } \\
\hline $\mathrm{CD}^{+}{ }^{+} \mathrm{CD}^{+}{ }^{+}$ & $6.7 \pm 5.9(1.4-18.8)$ \\
\hline$\alpha \beta$ TCR & $83.7 \pm 6.6(69.1-91.1)$ \\
\hline$\gamma \delta \mathrm{TCR}$ & $18.4 \pm 14.1(2.1-39.4)$ \\
\hline $\mathrm{CD}_{45 \mathrm{RO}^{+}}$ & $35.2 \pm 20.9(9.6-60)$ \\
\hline
\end{tabular}

$\mathrm{CD}^{+}{ }^{+} \mathrm{CD} 56^{+}, \mathrm{CD}^{+}{ }^{+} \mathrm{CD} 161^{+} \mathrm{CD} 56^{+}$and $\mathrm{CD} 3^{+} \mathrm{V} \alpha 24^{+}$are considered NKT cells.

(the current study was performed on high-quality segment IV biopsies during split liver transplantation). Despite these differences, it is obvious that the liver contains one of the human body's highest concentrations of NK cells. ${ }^{12,35}$ Hepatic NK cells are important for adaptive and innate immune responses in the liver, are involved in viral hepatitis, ${ }^{36,40}$ alcohol-related liver disease ${ }^{40}$ autoimmune liver disease and tumour control. ${ }^{37}$ They may be activated by NKT cells and are responsible for the liver injury associated with several liver diseases. ${ }^{37}$ By secreting cytokines, hepatic NK can also activate and recruit cytotoxic CD8 ${ }^{+} \mathrm{T}$ cells and eosinophils and enhance naïve CD4 ${ }^{+} \mathrm{T}$ cell differentiation into Th1 cells. ${ }^{35}$

The results of this study indicate that the normal human liver contains high numbers of lymphocytes that, due to their diverse phenotypic characteristics, may render the liver an important site for extrathymic lymphocyte development and maturation. Extrathymic lymphocyte development has also been proposed, in both mice and humans, to occur in the small intestine, omentum and uterus. ${ }^{41,42}$ IHL express genes that are necessary for T-cell differentiation, such as the recombination activation genes 1 and 2 (RAG1 and RAG2) and the pre-TCR $\alpha$ chain, ${ }^{4}$ which suggests that the liver is capable of sustaining development and proliferation of these cells. Hepatic lymphocyte levels are likely to be further boosted or maintained by cytokine-enhanced lymphocyte recruitment from the peripheral circulation $^{43,44}$ Such intrahepatic T-cell accumulation may also be a major disposal pathway for apoptosing
$\mathrm{CD}^{+}{ }^{+}$T-cells, ${ }^{45}$ and proliferation and apoptosis of murine $\mathrm{B} 220^{+} \mathrm{CD} 4{ }^{-} \mathrm{CD} 8^{-}{ }^{-}$cells. ${ }^{46}$ In this study, the apoptotic IHL component accounted for approximately $6 \%$ of IHL population in human liver. However, in situ perfusion with UW solution ${ }^{25}$ during the donor liver retrieval might lead to wash out of intrasinusoidal recruited apoptotic lymphocytes.

In summary, we have devised a multi-step modified protocol for IHL isolation, purification and phenotyping that resulted in increased cell viability and accuracy of IHL assessment. The modified protocol isolated slightly less proportions of the apoptotic IHL with higher viable and less dead cell proportions compared with the enzymatic dispersal protocol. Hence, the modified protocol may be the preferred technique for isolation of viable IHL suitable for culture and phenotyping. While the enzymatic dispersal protocol may be the preferred technique for isolation of representative population of liver lymphocytes including the apoptotic component of IHL. It is recommended to use positive or negative cell selection and fluorescence gating during FACS immunophenotyping of lymphocytes isolated from multicellular organs like liver. The data presented in this study also indicate that the human liver contains high numbers of IHL that were characterised by their heterogeneity and diversity. IHL are constituted by large numbers of $\mathrm{NK}$, NKT and $\mathrm{CD}^{+}$cells, high proportions of $\mathrm{CD}^{-} \mathrm{CD}^{-}, \mathrm{CD}^{+}{ }^{+} \mathrm{CD}^{+}{ }^{+}$and $\mathrm{TCR} \gamma \delta^{+}$cells. These findings stress the immunological importance of the liver and the techniques described will enable the functional characteristics of each particular IHL subset to be elucidated ex vivo.

\section{References}

1 Abo T, Watanab H, Ilai T, et al. Extrathymic pathways of $\mathrm{T}$ cell differentiation in the liver and other organs. Intern Rev Immunol 1994;11:61-102.

2 Sato K, Ohtsuka K, Hasegawa K, et al. Evidence for extrathymic generation of intermediate $\mathrm{T}$ cell receptor cells in the liver revealed in thymectomized, irradiated mice subjected to bone marrow transplantation. J Exp Med 1995;182:759-767.

3 Watanabe H, Miyaji C, Seki S, et al. c-kit+ stem cells and thymocyte precursors in the livers of adult mice. J Exp Med 1996;184:687-693.

4 Collins C, Norris S, McEntee G, et al. RAG1, RAG2 and pre-T cell receptor a chain expression by adult human hepatic $\mathrm{T}$ cells: evidence for extrathymic $\mathrm{T}$ cell maturation. Eur J Immunol 1996;26:3114-3118.

5 Norris S, Collins C, Doherty DG, et al. Resident human hepatic lymphocytes are phenotypically different from circulating lymphocytes. J Hepatol 1998;28:84-90.

6 Doherty DG, O'Farrelly C. Innate and adaptive lymphoid cells in the human liver. Immunol Rev 2000; 174:5-20.

7 Cantor HM, Dumont AE. Hepatic suppression of sensitization to antigen absorbed into the portal system. Nature 1967;215:744-745. 
8 Fleming KA. The anatomy of the normal liver and the hepatic lymphocyte. In: Crispe IN (ed). T Lymphocytes in the Liver. Immunobiology, Pathology and Host Defence. Wiley-Liss: New York, 1999, p 1.

9 Knolle P, Gerken G. Local control of the immune response in the liver. Immunol Rev 2000;174:21-34.

10 Mehal WZ, Azzaroli F, Crispe IN. Antigen presentation by liver cells controls intrahepatic T cell trapping, whereas bone marrow-derived cells preferentially promote intrahepatic $\mathrm{T}$ cell apoptosis. J Immunol 2001;167:667-673.

11 Calne RY, Sells RA, Pena JR, et al. Induction of immunological tolerance by porcine liver allografts. Nature 1969;223:472-476.

12 Norris S, Doherty DG, Collins C, et al. Natural T cells in the human liver: cytotoxic lymphocytes with dual $\mathrm{T}$ cell and natural killer cell phenotype and function are phenotypically heterogeneous and include Valpha24JalphaQ and gammadelta T cell receptor bearing cells. Hum Immunol 1999;60:20-31.

13 Si L, Whiteside TL, Van Thiel DH, et al. Lymphocyte subpopulation at the site of 'piecemeal' necrosis in end-stage chronic liver diseases and rejecting liver allografts in cyclosporin-treated patients. Lab Invest 1984;50:341-347.

14 Whiteside T, Lasky S, Si L, et al. Immunologic analysis of mononuclear cells in liver tissues and blood of patients with primary sclerosing cholangitis. Hepatology 1985;5:468-474.

15 Yoo YK, Gavaler JB, Chen K, et al. The effect of recombinant interferon-alpha on lymphocyte subpopulations and HLA-DR expression on liver tissue of HBV-positive individuals. Clin Exp Immunol 1990;82:338-343.

16 Dubuisson L, Boussarie L, Bedin CA, et al. Transformation of sinusoids into capillaries in a rat model of selenium-induced nodular regenerative hyperplasia: an immunolight and immunoelectron microscopic study. Hepatology 1995;21:805-814.

17 Goossens PL, Jouin H, Marchal G, et al. Isolation and flow cytometric analysis of the free lymphomyeloid cells present in murine liver. J Immunol Methods 1990;132:137-144.

18 Watanabe H, Ohtsuka K, Kimura M, et al. Details of an isolation method for hepatic lymphocytes in mice. J Immunol Methods 1992;146:145-154.

19 Hata K, Zhang XR, Iwatsuki S, et al. Isolation, phenotyping and functional analysis of lymphocytes from human liver. Clin Immunol Immunopathol 1990;56:401-419.

20 Li XM, Jeffers LJ, Reddy KR, et al. Immunophenotyping of lymphocytes in liver tissue of patients with chronic liver diseases by flow cytometry. Hepatology 1991;14:121-127.

21 Curry MP, Norris S, Golden-Mason L, et al. Isolation of lymphocytes from normal adult human liver suitable for phenotypic and functional characterization. J Immunol Methods 2000;242:21-31.

22 Wiltrout RH, Pilaro AM, Gruys ME, et al. Augmentation of mouse liver-associated natural killer activity by biologic response modifiers occurs largely via rapid recruitment of large granular lymphocytes from the bone marrow. J Immunol 1989;143: 372-378.

23 Abuzakouk M, Feighery C, O’farrelly C. Collagenase and dispase enzymes disrupt lymphocyte surface molecule. J Immunol Methods 1996;194:211-216.
24 Nursat AR, Wright SD, Aderem AA, et al. Properties of isolated red pulp macrophages from mouse spleen. J Exp Med 1988;168:1505-1510.

25 Olinga P, Merema M, Slooff MJ, et al. Influence of 48 hours of cold storage in University of Wisconsin organ preservation solution on metabolic capacity of rat hepatocytes. J Hepatol 1997;27:738-743.

26 Kinoshita K, Ikai I, Gomi T, et al. Exposure of hepatic sinusoidal mononuclear cells to UW solution in situ but not ex vivo induces apoptosis. J Hepatol 1998;29: 300-305.

27 Altman SA, Randers L, Rao G. Comparison of trypan blue dye exclusion and fluorometric assays for mammalian cell viability determinations. Biotechnol Prog 1993;9:671-674.

28 McCoy JP. Basic principles of flow cytometry. Hematol Oncol Clin North Am 2002;16:229-243.

29 Pruvot FR, Navarro F, Janin A, et al. Characterisation, quantification, and localisation of passenger T lymphocytes and NK cells in human liver before transplantation. Transpl Int 1995;8:273-279.

30 Hayday A, Theodoridis E, Ramsburg E, et al. Intraepithelial lymphocytes: exploring the Third Way in immunology. Nat Immunol 2001;2:997-1003.

31 McVay LD, Carding SR. Extrathymic origin of human $\gamma \delta \mathrm{T}$ cells during foetal development. J Immunol 1996;157:2873-2882.

32 Born W, Cady C, Jones-Carson J, et al. Immunoregulatory functions of $\gamma \delta$ T cells. Adv Immunol 1999;71: 77-144.

33 Nakajima H, Tomiyama H, Takiguchi M. Inhibition of gamma delta $\mathrm{T}$ cell recognition by receptors for MHC class I molecules. J Immunol 1995;155:4139-4142.

34 Ferrarini M, Heltai S, Pupa SM, et al. Killing of laminin receptor positive human lung cancer by tumour-infiltrating lymphocytes bearing $\gamma \delta^{+} \mathrm{T}$ cell receptors. J Natl Cancer Inst 1996;88:436-441.

35 Doherty DG, Norris S, Madrigal-Estebas L, et al. The human liver contains multiple populations of NK cells, T cells, and CD3+CD56+ natural $\mathrm{T}$ cells with distinct cytotoxic activities and Th1, Th2, and Th0 cytokine secretion patterns. J Immunol 1999;163: 2314-2321.

36 Yonekura K, Ichida T, Sato K, et al. Liver-infiltrating CD56 positive $\mathrm{T}$ lymphocytes in hepatitis $\mathrm{C}$ virus infection. Liver 2000;20:357-365.

37 Kita H, Kronenberg M, Gershwin ME. Intrahepatic NKT cells. In: Gershwin ME, Vierling JM, Manns MP (eds). Liver Immunology. Hanley and Belfus: Philadelphia, 2002, pp 85-98.

38 Morsy MA, Norman PJ, Rela M, et al. Phenotyping of intrahepatic lymphocytes in human donor liver. Hepatology 2001;34:495.

39 Hata K, Van Thiel D, Herberman RB, et al. Natural killer activity of human liver-derived lymphocytes in various liver diseases. Hepatology 1991;14:495-503.

40 Morsy MA, Norman PJ, Gonde C, et al. Hepatic Lymphocyte Expression of Activation Markers and Adhesion Integrins in Hepatitis C- and AlcoholRelated Chronic Liver Disease: Immunohistochemical and Flow Cytometric Study. Liver and Gut Immunology. Falk Symposium: Freiburg-Germany, 2003.

41 Rocha B, Guy-Grand D, Vassalli P. Extrathymic T cell differentiation. Curr Opin Immunol 1995;7:235-242.

42 Suzuki K, Oida T, Hamada H, et al. Gut cryptopatches: Direct evidence of extrathymic anatomical sites for intestinal T lymphopoiesis. Immunity 2000;13:691-702. 
43 Butcher EC, Picker LJ. Lymphocyte homing and homeostasis. Sience 1996;272:60-66.

44 Leite-De-Moraes MC, Moreau G, Arnould A, et al. IL-4producing NK T cells are biased towards IFN-gamma production by IL-12. Influence of the microenvironment on the functional capacities of NK T cells. Eur J Immunol 1998;28:1507-1515.
45 Crispe N, Mehal WZ. Strange brew: T cells in the liver. Immunol Today 1996;17:522-525.

46 Huang L, Sye K, Crispe IN. Proliferation and apoptosis of B220+CD4-CD8-TCR alpha beta intermediate $\mathrm{T}$ cells in the liver of normal adult mice: implication for Ipr pathogenesis. Int Immunol 1994;6: 533-540. 